\title{
WestVirginiaUniversity
}

THE RESEARCH REPOSITORY @ WVU

Graduate Theses, Dissertations, and Problem Reports

2000

\section{Limits of sensitivity to delayed timeout from avoidance}

Chad Michael Galuska

West Virginia University

Follow this and additional works at: https://researchrepository.wvu.edu/etd

\section{Recommended Citation}

Galuska, Chad Michael, "Limits of sensitivity to delayed timeout from avoidance" (2000). Graduate Theses, Dissertations, and Problem Reports. 870.

https://researchrepository.wvu.edu/etd/870

This Thesis is protected by copyright and/or related rights. It has been brought to you by the The Research Repository @ WVU with permission from the rights-holder(s). You are free to use this Thesis in any way that is permitted by the copyright and related rights legislation that applies to your use. For other uses you must obtain permission from the rights-holder(s) directly, unless additional rights are indicated by a Creative Commons license in the record and/ or on the work itself. This Thesis has been accepted for inclusion in WVU Graduate Theses, Dissertations, and Problem Reports collection by an authorized administrator of The Research Repository @ WVU. For more information, please contact researchrepository@mail.wvu.edu. 
Limits of Sensitivity to Delayed Timeout from Avoidance

Chad M. Galuska

\begin{abstract}
A Thesis
Submitted to the Eberly College of Arts and Sciences

of
\end{abstract}

West Virginia University

in Partial Fulfillment of the Requirements for

The Degree of Master of the Arts

in

Psychology

Michael Perone, Ph.D. (Chair)

Kennon A. Lattal, Ph.D.

Stanley H. Cohen, Ph.D.

Department of Psychology

Morgantown, West Virginia

2000

Keywords: molar and molecular response-reinforcer relations, negative reinforcement, timeout from avoidance, delay, contiguity, chain schedules, variable-cycle avoidance 


\section{ABSTRACT \\ Limits of Sensitivity to Delayed Timeout from Avoidance}

Chad M. Galuska

Session-reduction procedures have been employed to assess molar control of avoidance responding. By conceptualizing session reduction as a delayed timeout from avoidance, the present study investigated the limits of molar control while minimizing several methodological limitations inherent in such procedures. Six times during each session, a two-link chain schedule was superimposed on a baseline schedule of variable-cycle shock avoidance. Completion of the initial link (fixed-ratio 10 schedule) produced a timeout following a signaled delay during which the avoidance schedule remained operative. For most rats, the delay was manipulated across conditions from $0 \mathrm{~s}$ to $60 \mathrm{~s}$. Control by the delayed timeout was indicated by elevated initial-link responding relative to baseline avoidance responding. Reliable initial-link elevations were obtained only when the timeout was presented immediately upon the completion of the initial link. These findings cast doubt on previous interpretations of session-reduction as molar reinforcement, and underscore the importance of response-reinforcer contiguity. 


\section{Acknowledgments}

I would like to thank the members of my committee, Michael Perone, Andy Lattal, and Stan Cohen, for their helpful suggestions during both the proposal of this research and during the defense meeting.

I am extremely grateful to Michael Perone, who served as both the committee chair and faculty advisor of this project. Mike's guidance has been invaluable from the conception of this project, and I especially would like to thank him for his substantial comments and suggestions of earlier drafts of this manuscript.

Thanks to Leo Carlin, for programming assistance in the initial stages of this research project. I also would like to thank Todd Myers, for the use of preliminary training programs as well as for his conceptual contributions throughout this project.

Tammy Wade deserves much credit for doing the little things that often are overlooked, but are necessary to make an extended project like this feasible.

Finally, this project would not have been possible without the love and support from my family and friends. 


\section{Table of Contents}

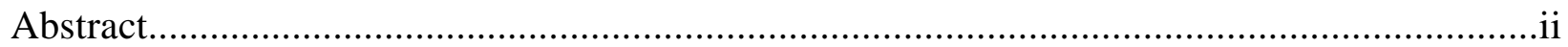

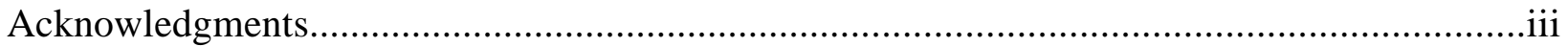

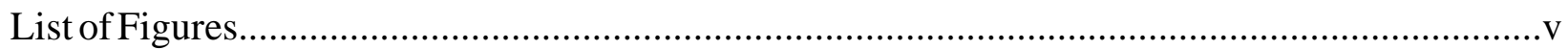

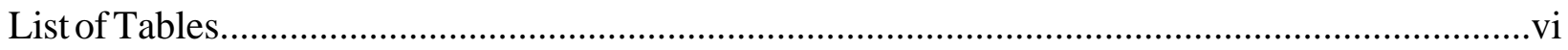

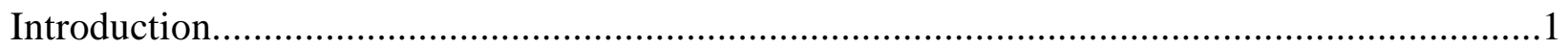

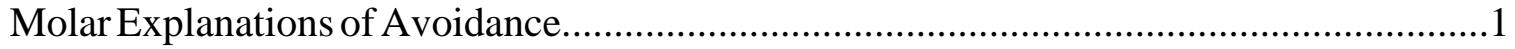

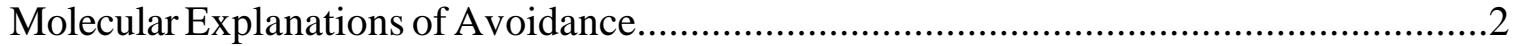

Session Reduction as Negative Reinforcement...................................................

Session Reduction as Timeout from Avoidance.............................................................5

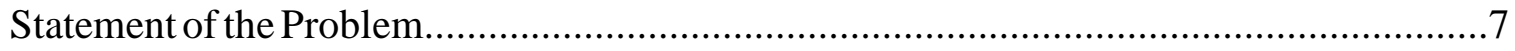

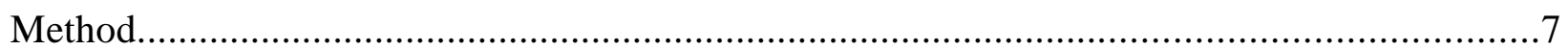

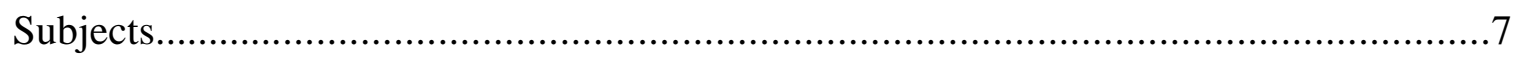

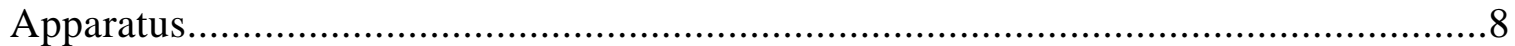

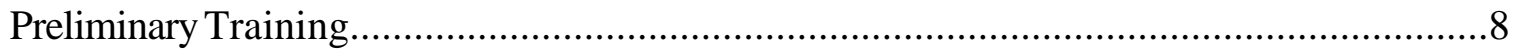

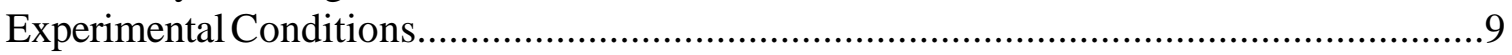

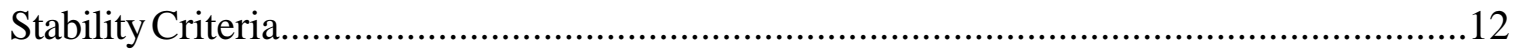

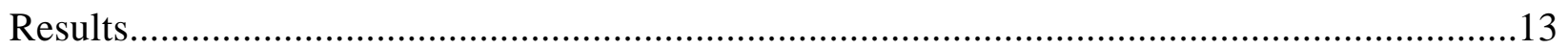

Baseline and Initial-Link Response Rates Across Delay Values...................................13

Latency to Respond in the Initial Link............................................................. 17

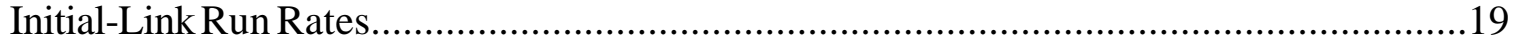

Terminal-Link Response Rates..........................................................................22

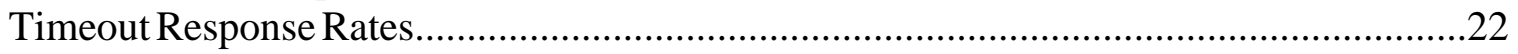

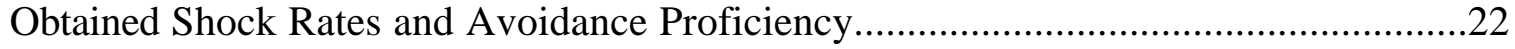

Resistance to Change in Schedules of Avoidance and Escape.......................................25

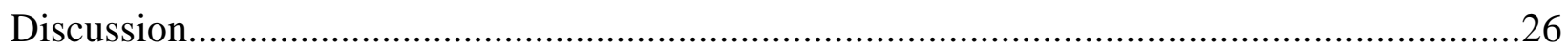

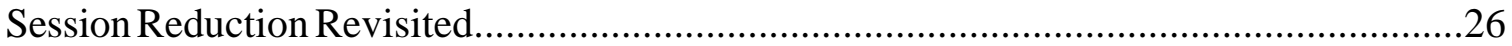

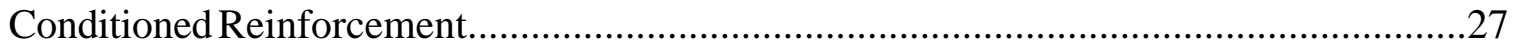

Shock-Frequency Reduction vs. Effort Reduction..............................................27

Molecular Patterns of Responding ..................................................................28

Adventitious Reinforcement of Responding during the Delay to Timeout........................30

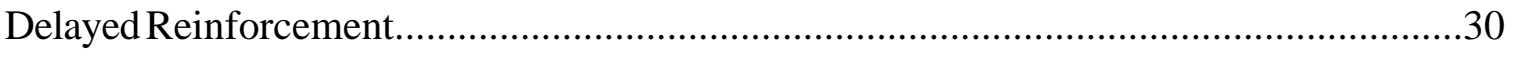

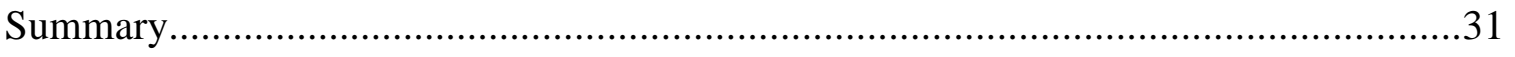

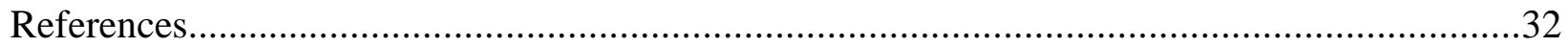




\section{List of Figures}

Figure 1. Response rates during the baseline and initial link ............................................ 14

Figure 2. Initial-link to baseline response ratios ..........................................................16

Figure 3. Group initial-link to baseline response ratios ......................................................17

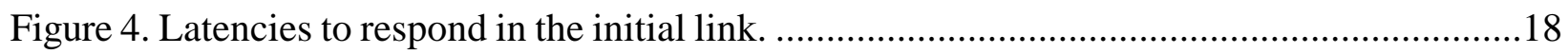

Figure 5. Group latencies to respond in the initial link .................................................... 19

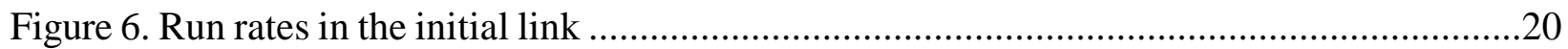

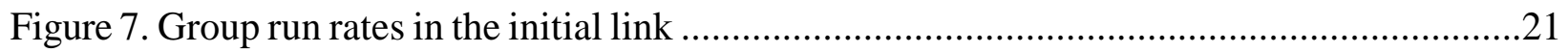

Figure 8. Response rates during the baseline and terminal link ...........................................23

Figure 9. Resistance to change in the baseline and initial-link response rates ..........................25 


\section{List of Tables}

Table 1. Stimuli associated with the links of the chain schedule ............................................. 10

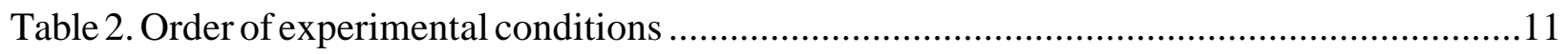

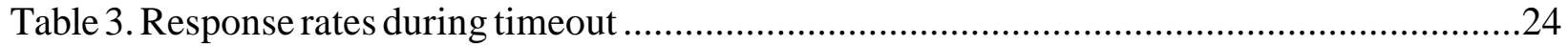

Table 4. Obtained shock rates and avoidance proficiencies ..................................................24 


\section{Introduction}

Negative reinforcement can be defined as the strengthening of behavior through the termination, prevention, or postponement of an aversive stimulus. Behavior maintained by negative reinforcement has been divided into two categories. Escape is maintained by the termination of an ongoing aversive stimulus. Avoidance is maintained by the prevention or postponement of an aversive stimulus.

Avoidance has long fueled theoretical debate (for reviews see Dinsmoor, 1977; Herrnstein, 1969; and Hineline, 1984), because the immediate consequences of such behavior are not clear. Unlike escape responding which terminates an ongoing aversive stimulus, free-operant avoidance responses have no immediate, conspicuous effect on the environment. Consider the free-operant avoidance procedure developed by Sidman (1953). In the absence of responding, brief shocks were delivered to rats at short, regular intervals known as the shock-shock (SS) interval. Each lever press delayed the next scheduled shock for another period, usually longer, known as the response-shock (RS) interval. Thus, the rats could postpone shock indefinitely be steady responding at intervals less than the RS interval. Lever pressing was maintained even though rats rarely came into contact with shock. To the casual observer, the environment immediately preceding a lever press was identical to the environment immediately following a lever press, as both were shock-free periods.

If behavior is maintained by its consequences, what are the consequences that maintain avoidance behavior? Two types of explanations have been offered. Molar explanations of avoidance state that behavior is sensitive to diffuse, long-term consequences which are temporally extended and have no clear locus in time. In particular, one-factor theorists point to the long-term correlation between response rate and shock frequency.

\section{Molar Explanations of Avoidance}

Sidman (1962a) was among the first to suggest that overall reductions in shock frequency could serve as the reinforcer for avoidance. The empirical basis for his suggestion came from an experiment in which rats could avoid shock on two concurrent schedules of shock postponement, each associated with its own lever. Responding on one lever postponed shock by $40 \mathrm{~s}$. Responding on the other postponed shock by $20 \mathrm{~s}$. In the absence of responding, more shocks were programed on the lever that postponed shock by $20 \mathrm{~s}$. The rats tended to favor the lever that 
postponed shock by $20 \mathrm{~s}$ because this pattern of responding led to greater shock-frequency reduction.

Herrnstein and Hineline (1966) contended that reductions in shock rate alone are sufficient to maintain avoidance responding. In Herrnstein and Hineline's procedure, shocks were delivered randomly in time according to one of two schedules. For example, in one condition the probability of receiving a shock in any 2-s period was 0.3. A single response switched control of shock delivery to a less dense schedule where the probability of receiving a shock in any 2-s period was 0.1. The delivery of the next shock returned control to the dense schedule. No stimuli were associated with the two schedules, and the random-time schedule eliminated temporal regularities between responses and shocks. Thus, responding decreased overall shock frequency but did not guarantee a shock-free period following each response. Herrnstein and Hineline reported their procedure maintained responding in 17 of 18 rats.

\section{Molecular Explanations of Avoidance}

Molecular theorists raise doubt about the extent to which remote consequences such as shock frequency can control behavior. Dinsmoor (1977) argued that because shock-frequency reduction is a continuous event aggregated over time it is impossible for it to become correlated with a specific event such as lever pressing. Therefore, shock-frequency reduction alone is not sufficient to maintain responding. Dinsmoor stated that behavior is not controlled by shock-frequency reduction, but rather by immediate - albeit inconspicuous - changes in the environment following a response.

Anger (1963) proposed that temporal regularities inherent in conventional avoidance procedures could acquire conditioned aversive properties. In Sidman's (1953) procedure, each shock is preceded by a fixed period of time since the last response, that is, the RS interval. According to Anger, the passage of time since an avoidance response acquires conditioned aversive properties by being paired with shock. The aversive aspects of the passage of time drops to a minimum after a response because shocks are never delivered immediately following a response. Dinsmoor (1977) has characterized the stimuli immediately following a response as safety signals. In general, two-factor theories of avoidance state that subtle features in the environment that are paired with a particular aversive stimulus such as shock can acquire conditioned aversive properties through Pavlovian conditioning, and thus function as warning 
signals (Dinsmoor, 1977).

Two-factor theories can accommodate results that traditionally have supported one-factor accounts of avoidance, such as the results reported by Herrnstein and Hineline (1966). In Herrnstein and Hineline's procedure, Dinsmoor (1977) observed that the probability of receiving a shock immediately following a lever press was lower than the probability of shock in the absence of a lever press. In Pavlovian terms, the conditioned stimulus - unconditioned stimulus (CS - US) interval between the stimuli that accompanied a lever press and shock delivery was longer, on the average, than the CS - US interval between the stimuli that accompanied any other behavior and shock delivery. Thus, stimuli that accompanied lever pressing functioned as conditioned negative reinforcers (i.e., safety signals).

\section{Session Reduction as Negative Reinforcement}

Both molar and molecular explanations of avoidance adequately describe conventional avoidance procedures based on shock postponement (Sidman, 1953) or shock deletion (de Villiers, 1972). Unconventional procedures have been employed to settle the issue. One such procedure was reported by Mellitz, Hineline, Whitehouse, and Laurence (1983). Rats' presses on two levers postponed shock according to a single avoidance schedule, with an RS interval of $20 \mathrm{~s}$ and an SS interval of $10 \mathrm{~s}$. In addition, presses on one of the levers - the conjoint lever subtracted $1 \mathrm{~min}$ from the total session time, which by default was set at $152 \mathrm{~min}$. While presses on both levers postponed shock in the short term, presses on the conjoint lever also led eventually - to the early end of the avoidance session and, therefore, to reduced contact with shock. The session-reduction contingency was turned off during the last 2 min of each session to avoid contiguity between a lever press and the session offset. The procedure was continued until there was a preference for the conjoint lever for 3 consecutive sessions, with a minimum of 5 sessions in each condition. In subsequent conditions, the session-reduction contingency was moved back and forth across the levers. Mellitz et al. reported that 2 of the 5 rats preferred the conjoint lever and tracked it across some of the reversals, thus exhibiting sensitivity to reductions in session duration.

Perone and Day (1986) questioned the adequacy of Melltiz et al.'s (1983) experiment on two fronts. First, Perone and Day questioned whether preference for the conjoint lever actually was established. Mellitz et al. switched conditions immediately after a preference for the conjoint 
lever was demonstrated for 3 consecutive sessions, regardless of the rats' past performance. Although some conditions lasted as few as 5 sessions, others lasted as long as 20 sessions. Yet only the last 3 sessions were used to determine preference. Theoretically, the behavior of the rats could be modeled with a coin flip, with conditions being terminated as soon as a run of 3 heads was obtained.

Perone and Day (1986) also suggested that hidden molecular contingencies might have been operating in the Mellitz et al. (1983) experiment. Although the session-reduction contingency was turned off during the last 2 min of each session, contiguity between a conjoint response and the termination of a session could have occurred.

To address these methodological issues, Perone and Day (1986) performed a systematic replication of the Mellitz et al. (1983) experiment. Two levers operated a single schedule, with an RS interval of $30 \mathrm{~s}$ and an SS interval of $5 \mathrm{~s}$. In addition, presses on one of the levers subtracted 1 min from the 152-min session. The session-reduction contingency was alternated between the levers across 5 blocks of 20 sessions. Perone and Day hypothesized that longer conditions were necessary to establish whether the outcomes Mellitz et al. reported were truly preferences, transitory phenomena, or normal fluctuations in response allocation (akin to the coin-flip analogy), as described by Verhave (1961) and discussed below.

In general, Perone and Day (1986) found little evidence to suggest that the session-reduction contingency controlled behavior. Preference for the conjoint lever was weak and unreliable across reversals.

In a second experiment, Perone and Day (1986) established a "must-press" contingency on the conjoint lever. When the session time had elapsed, a press on the conjoint lever was required to terminate the session. The addition of this molecular contingency ensured contiguity between a press of the conjoint lever and the offset of the avoidance session. Still, Perone and Day failed to establish preference for the conjoint lever.

The failure of Perone and Day (1986) to replicate Mellitz et al.'s (1983) findings - even with the addition of molecular contingencies - suggests a possible flaw in procedures designed to study reductions in session duration as negative reinforcement. In both the Mellitz et al. and the Perone and Day experiments, the rats contacted the session-reduction contingency only at the termination of the session. Perhaps sensitivity to reductions in session duration could be increased 
if it were possible for rats to contact the session-reduction contingency more than once per session.

The two-lever procedure employed in the Mellitz et al. (1983) and the Perone and Day (1986) experiments also warrants consideration. Relevant data come from an experiment by Verhave (1961). Verhave employed a two-lever avoidance procedure where presses on either lever postponed shock according to a single schedule of shock avoidance (RS $30 \mathrm{~s}, \mathrm{SS} 1.5 \mathrm{~s}$ ). This is the basic arrangement used by Mellitz et al. and Perone and Day, except that no session-reduction contingency was employed. Although the rats eventually responded predominantly on one lever, sudden switches in preference often occurred for no obvious reasons. Switches in preference sometimes occurred at the beginning of a session, and at other times in the midst of a session. Verhave noted that in 4 out of 8 rats, preference shifted back and forth abruptly between the two levers in a single session. Gradual shifts also occurred. For example, the rate of responding for one rat was higher on one lever than on the other for 19 consecutive sessions. Beginning on Session 20, however, preference shifted for the next 5 sessions. These results cast serious doubt on the methodological adequacy of Mellitz et al.'s experiment and suggest that a one-lever procedure may serve as a better template from which to assess the sensitivity to reductions in session duration.

A final problem with procedures designed to study session reduction as negative reinforcement is that the magnitude of session reduction is not experimentally controlled, but rather is dependent on the behavior of the subject. In both the Mellitz et al. (1983) and Perone and Day (1986) experiments, session duration varied widely on a day-to-day basis. Fluctuations in session duration also limit interpretation of the preference results. For example, at the onset of a session, if a rat made150 responses on the conjoint lever, the session would end after a few minutes, even though the rat may have switched to the nonconjoint lever if the session had continued.

\section{Session Reduction as Timeout from Avoidance}

Session-duration-reduction can be viewed as an extended timeout from avoidance at the end of an avoidance session. Timeout from avoidance previously has been shown to function as an effective reinforcer (e.g., Perone \& Galizio, 1987). Conceptualized as timeout from avoidance, the magnitude of the reduced contact with shock contingency can be controlled experimentally 
and presented more than once per session. Although most studies utilizing timeout from avoidance have employed two-lever procedures, a one-lever procedure developed by DeWaard, Galizio, and Baron (1979) may be adapted to address the above concerns regarding traditional procedures studying session reduction. Because of the importance of the DeWaard et al. procedure to the present experiment, it is necessary to describe it in some detail.

DeWaard et al. (1979) employed a variable-cycle (VC) 60-s schedule of shock avoidance, which programmed shocks at irregular intervals averaging $60 \mathrm{~s}$. The rats' first response in an interval canceled the shock programmed at the end of the interval. Further responses during the interval had no effect. This schedule generates steady but moderate rates of responding.

A two-link chain schedule was then superimposed on the VC 60-s schedule 6 times during the session at irregular intervals. During the initial link, a fixed-ratio (FR) 10 requirement controlled access to the terminal link. In the terminal link, a different VC schedule operated. The VC value in the terminal link was varied across conditions so that the scheduled shock frequency in the terminal link was varied from 0 shocks per min (timeout from avoidance) to 8 shocks per $\min (\mathrm{VC} 7.5 \mathrm{~s})$.

The links of the chain schedule were signaled by the houselight. For all of the rats, the houselight flashed on and off in 0.5-s cycles during the initial link. For half of the rats, the houselight was on in the terminal link and off between presentations of the chain schedule (baseline). The stimuli were reversed for the other rats.

DeWaard et al. (1979) reported that response rates in the initial link were an inverse function of the shock rates obtained in the terminal link. Response rates in the terminal link, by comparison, were related positively to the scheduled shock rate. When timeout was scheduled in the terminal link, response rates in the initial link increased above baseline levels. When a VC 60-s schedule operated during the terminal link as well as the baseline and initial link, response rates remained relatively stable across the links. Finally, as scheduled shock rates in the terminal link increased above baseline and initial-link levels, response rates in the initial link were suppressed.

In the present experiment, a variation of the procedure developed by DeWaard et al. (1979) was utilized to examine the sensitivity to delayed reductions in contact with shock avoidance schedules. Completion of the initial link produced a terminal link that included a timeout from avoidance presented after some delay. The duration of the delay was manipulated 
across conditions and signaled (to maximize control by the molar contingencies). To the extent that behavior is sensitive to the delayed timeout, initial-link responding should be elevated relative to baseline.

\section{Statement of the Problem}

Session-reduction procedures (Mellitz et al., 1983; Perone \& Day, 1986) have attempted to demonstrate molar control of avoidance responding. Previous research has met with several limitations. First, contact with the molar contingency was made available only once per session, that is, at the end of the session. Second, interpretation of preference data from two-lever procedures operating a single avoidance schedule becomes clouded in light of the data reported by Verhave (1961). Finally, the magnitude of session reduction was not controlled experimentally, but rather was dependent on the behavior of the subject.

In the present experiment, a variation of the procedure employed by DeWaard et al. (1979) provided a novel strategy to study the extent to which reduced contact with an avoidance schedule (via timeout from avoidance) functioned as a reinforcer. Control by the delayed timeout was assessed by changes in response rate, rather than preference. Occasionally during each session, a two-link chain schedule was superimposed on a baseline schedule of VC avoidance. In the initial link, completion of an FR 10 arranged access to a terminal link consisting of timeout from avoidance following a signaled delay during which the $\mathrm{VC}$ schedule remained operative. For most rats, the delay to timeout was manipulated across conditions from $0 \mathrm{~s}$ to $60 \mathrm{~s}$. To the extent that decreased contact with the avoidance schedule functions as negative reinforcement, initial-link response rates should be elevated relative to the response rates generated by the VC avoidance schedule. Initial-link enhancement across delay values would indicate control by molar contingencies, similar to the session-reduction results reported by Mellitz et al. (1983).

\section{Method}

\section{Subjects}

Eight naive male albino rats were housed individually under a reversed $12 \mathrm{hr}$ light/dark cycle. Sessions were conducted during the dark part of the cycle. To prevent fouling on the shock grid, the rats were food deprived for approximately $15 \mathrm{hr}$ preceding each experimental session. Free access to water was available in the homecages, although in the course of the experiment it became necessary to water deprive Rats C3, C6, and C7 in a further effort to prevent electrical 
shortages on the shock grid. Water deprivation was accomplished in a similar manner as food deprivation.

\section{Apparatus}

Two custom-built operant chambers and two commercial chambers (Lehigh Valley Electronics) were used. The interiors were approximately $30 \mathrm{~cm}$ long, $21 \mathrm{~cm}$ high, and $19 \mathrm{~cm}$ deep. The side walls and ceilings in each commercial chamber were constructed of Plexiglass, and the end walls with stainless steel. The floor consisted of stainless steel rods, $0.5 \mathrm{~cm}$ in diameter, spaced $1.9 \mathrm{~cm}$ apart, center to center. General illumination was provided by a $28-\mathrm{V}$ houselight (No. 1820) mounted behind a sheet of white paper on a side wall. Each chamber was enclosed in a sound-attenuating box equipped with a fan for ventilation and a speaker for white noise $(75 \mathrm{~dB})$. In the custom-built chambers, the rear wall, ceiling, and one side wall were constructed of clear Plexiglass, the other side wall of stainless steel, and the front wall of aluminum. In all four chambers, two levers were centered $10 \mathrm{~cm}$ apart on the front wall, $9 \mathrm{~cm}$ above the grid floor. An additional cuelight was centered $4 \mathrm{~cm}$ above each lever. The left lever remained retracted throughout the experiment, and the cuelights above both levers remained inoperative. The right

lever, used during the experiment, required a force of $0.3 \mathrm{~N}$ to operate. Each press of the right lever resulted in a 0.5-s white noise offset. Scrambled shock of 1-mA intensity and 0.5-s duration was delivered from Grason-Stadler shock generators (E1064GS). Shock was delivered through the floor, the walls, and the levers. Control and recording operations were accomplished with microcomputers connected to the chambers via digital interfaces (Computer Boards, Inc., CIO-PDIS08).

\section{Preliminary Training}

With the exception of the first few sessions, preliminary training sessions lasted $4 \mathrm{hr}$ and were scheduled 3 days per week. For the remainder of the experiment, sessions were conducted only 3 days per week, due to the relatively long avoidance sessions. The beginning of the session was signaled by the onset of the white noise and the session terminated with the offset of the white noise. During preliminary training and thereafter, sessions were conducted with the houselight on for Rats C2, C4, C5, and C7, and off for Rats C1, C3, C6, and C8.

Lever pressing was shaped in a single session, using a procedure similar to one described by Baron (1991, pp. 181-182). Each lever press was followed by an offset of white noise for $1.5 \mathrm{~s}$ 
and initiated a shock-free interval that was reduced over the course of several sessions to $60 \mathrm{~s}$. The white noise offset following each response also was reduced to a terminal value of $0.5 \mathrm{~s}$.

After lever pressing was established, a Sidman (1953) avoidance procedure was in effect for approximately 10 sessions, until the rats were avoiding over $80 \%$ of the scheduled RS shocks. In the absence of responding, a shock was delivered every $5 \mathrm{~s}$ (SS $5 \mathrm{~s}$ ). Each response initiated a shock-free interval of $60 \mathrm{~s}$ (RS $60 \mathrm{~s}$ ). Informal observations in our laboratory have indicated that preceding VC training with Sidman avoidance enhances avoidance proficiency.

A VC 60-s schedule then was employed. A VC schedule consists of intervals, or cycles, similar to a variable-interval (VI) schedule of positive reinforcement. On the average of once per $60 \mathrm{~s}$, the VC schedule programmed shocks at 12 irregular intervals using Fleshler and Hoffman's (1962) distribution, modified so that the minimum intershock interval was $5 \mathrm{~s}$ and the maximum intershock interval was $210 \mathrm{~s}$. In a VC schedule, the first response in an interval or cycle cancels the shock programmed at the end of the interval. Further responses during the interval have no effect. If no response is made during any interval, a shock is delivered at the end of the interval. In addition, whenever a shock was delivered from the VC schedule, the VC schedule was suspended and additional shocks were delivered every $5 \mathrm{~s}$ until a response occurred. The addition of an SS timer onto a VC schedule has been shown to facilitate the acquisition and maintenance of responding (DeWaard, et al., 1979; Courtney \& Perone, 1992). When a response was made during the SS period, the VC schedule was reinstated and another lever press was required to cancel the shock programmed at the end of the interval. That is, SS responses terminated the chain of SS shocks but did not cancel the next programmed VC shock. Training on the VC 60-s schedule lasted approximately 15 - 20 sessions, until the rats were avoiding at least $80 \%$ of the scheduled VC shocks.

\section{Experimental Conditions}

In the experimental conditions, 6 times during each session a two-link chain schedule was superimposed on the VC 60-s schedule. The introduction of the first chain schedule occurred 30 min into the session. Thereafter, presentations of the chain schedule were separated by a mean interval of $20 \mathrm{~min}$, with a range of 10 to $30 \mathrm{~min}$, during which the $\mathrm{VC}$ schedule remained operative. For the remainder of this paper, the $5 \mathrm{~min}$ period preceding each presentation of the chain schedule will be referred to as the baseline. The session ended $30 \mathrm{~min}$ after the completion 
Table 1

Stimuli used in the baseline (BL), initial link (IL), and the variable-cycle (VC) and timeout (TO) components of the terminal link (TL).

\begin{tabular}{cccccc} 
& & & \multicolumn{3}{c}{ TL } \\
\cline { 5 - 6 } Rat & Stimulus & BL & IL & VC & TO \\
\hline \hline \multirow{2}{*}{ C2, C4, C5, C7 } & White Noise & On & On & On & Off \\
& Houselight & On & Flash & Off & Off \\
\hline \multirow{2}{*}{ C1, C3, C6, C8 } & White Noise & On & On & On & Off \\
& Houselight & Off & Flash & On & Off \\
\hline \hline
\end{tabular}

of the last chain schedule.

The initial link was signaled by a flashing (0.5-s on, 0.5 -s off) houselight. In the initial link, an FR 10 was arranged conjointly with the VC 60-s schedule. Completion of the FR requirement produced the terminal link.

The terminal link was signaled by the onset of the houselight for Rats $\mathrm{C} 1, \mathrm{C} 3, \mathrm{C} 6$, and C8, and the offset of the houselight for Rats C2, C4, C5, and C7. The terminal link consisted of some delay, during which the VC schedule remained in effect, followed by timeout from avoidance. During timeout, the houselight and white noise were turned off. Table 1 summarizes the stimuli correlated with the various segments of the session.

The delay to timeout was manipulated across conditions. For Rats C1, C2, C3, and C7, the entire terminal link was fixed at 8 min (fixed terminal link). Thus, the amount of time spent in timeout varied across conditions ( 8 min minus the delay to timeout). For Rats C4, C5, C6, and $\mathrm{C} 8$, the magnitude of the timeout was fixed at $5 \mathrm{~min}$ (fixed timeout), and thus the duration of the terminal link varied across conditions as a function of the delay to timeout. The purpose of the fixed timeout was to assess for confounds of delay and timeout duration, as greater delays yield shorter timeouts in the fixed terminal link group.

Table 2 summarizes the order of the experimental conditions, as well as the number of sessions in each condition. For all rats, the first condition of the experiment consisted of the 


\section{Table 2}

Order of experimental conditions. The number of sessions in each condition is shown in parentheses

Delay to Timeout (s)

\begin{tabular}{|c|c|c|c|c|c|c|}
\hline Rat & No Timeout & 0 & 15 & 30 & 60 & 120 \\
\hline $\mathrm{C} 1$ & $1(16)^{*}, 6(13)$ & $2(28)^{*}, 3(16), 8(10)$ & $7(17)$ & $4(24)$ & $5(15)$ & --- \\
\hline $\mathrm{C} 2$ & $1(21), 5(15)$ & $2(36), 7(13)$ & $4(18)$ & $3(19)$ & $6(23)$ & --- \\
\hline $\mathrm{C} 3$ & $1(16)^{*}, 6(11)$ & $2(39)^{*}, 3(28)$ & $5(25)$ & $4(18)$ & --- & --- \\
\hline $\mathrm{C} 4$ & $1(16), 6(10)$ & $2(48)$ & $8(18)$ & $3(33), 7(12)$ & $4(16)$ & $5(14)$ \\
\hline C6 & $1(17), 7(25)$ & $2(38), 6(12)$ & $5(16), 8(10)$ & $3(21)$ & $4(23)$ & --- \\
\hline $\mathrm{C} 7$ & $1(14), 7(12)$ & $2(38), 5(14), 8(13)$ & $6(16)$ & $3(18)$ & $4(21)$ & --- \\
\hline $\mathrm{C} 8$ & $1(12)$ & $2(31), 5(10)$ & $4(10)$ & $3(14), 6(12)$ & $7(14)$ & --- \\
\hline
\end{tabular}

Note. The symbol * represents conditions in which the VC 60-s schedule operated. The results from these conditions are not reported, as the schedule value was changed to $120 \mathrm{~s}$ for these rats. 
entire terminal link (8 min) spent in VC avoidance. This no-timeout control condition allowed for an estimation of stimulus bias and provided a basis of comparison for initial-link elevations in subsequent conditions. The second condition for all rats consisted of the entire terminal link (5 or $8 \mathrm{~min}$ ) spent in timeout from avoidance. This condition, a replication of a condition from DeWaard et al.'s (1979) experiment, tested whether our laboratory was able to produce enhanced initial-link responding under maximally reinforcing terminal-link conditions.

At this point the procedure had to be modified for Rats C1, C3, and C5, who after 28, and 39,30 sessions, respectively, did not exhibit enhanced initial-link responding relative to baseline. A comparison of the response rates in the present experiment and the response rates obtained by DeWaard et al. (1979) suggested that a ceiling effect may have been operating. Differences in response rates between the two studies probably were the result of a higher force requirement on the lever in the DeWaard et al. study. In an effort to lower overall response rates for Rats C1, C3, and $\mathrm{C} 5$, the VC parameter was changed from $60 \mathrm{~s}$ to $120 \mathrm{~s}$, with a minimum intershock interval of $10 \mathrm{~s}$ and a maximum intershock interval of $413 \mathrm{~s}$. This schedule was used with these rats for the remainder of the experiment.

Across conditions, delay values of $0,15,30,60$, and 120 s were investigated. With the exception of Rat C3, who died before completing the 60-s delay condition, all rats were exposed to the $0,15,30$, and 60 -s delays. In addition, Rat C4 was exposed to the 120-s delay, because C4 exhibited elevated initial-link response rates at the 60-s delay. With the exception of Rats C3 and $\mathrm{C} 4$, the 0-s delay condition was replicated in all rats. The no-timeout control condition also was

replicated for most rats (Rat C8 died before the no-timeout condition could be replicated), and some rats received additional replications of various delay conditions. Due to the change from a VC 60 to VC 120-s schedule, the no-timeout condition was replicated at VC 120 for Rats C1, C3, and C5. Only data from this condition are shown.

\section{Stability Criteria}

Each condition lasted a minimum of 10 sessions until response rates were stable in the baseline and initial link. The stability criteria were as follows. In the absence of a trend, the mean response rates in the first 3 sessions and last 3 sessions of 6 consecutive sessions had to be within $15 \%$ of the overall mean of the 6 sessions. The response rates used to assess stability were based on the entire session, aggregated across all 6 chain presentations. 


\section{Results}

No differences were found with respect to terminal-link duration (fixed terminal- link duration versus fixed timeout duration) or the stimuli signaling the baseline and terminal links (houselight on or off). Therefore the data will be presented without further mention of these procedural differences.

\section{Baseline and Initial-Link Response Rates Across Delay Values}

Figure 1 shows the average response rates in the baseline (open circles) and initial link (filled circles). Disconnected triangles represent replications (and will in each subsequent figure). The averages are based on the 36 individual chain presentations and the immediately preceding 5 -min baseline periods from the stable 6 sessions of each condition. Unless otherwise noted, all single-subject results reported in this experiment will be based on the individual link data. Inspection of these data revealed that response rates were skewed. Therefore, medians and interquartile ranges are presented.

With the exception of Rat C2, whose baseline behavior drifted upward across delay values, baseline response rates remained relatively constant across all conditions. When timeout was not presented in the terminal link (No TO), baseline and initial-link response rates did not differ systematically, although stimulus biases were evident in the behavior of half of the rats (Rats C1, C2, C6, and C8). For Rats C4 and C7, initial-link response rates were elevated in the replication of the no-timeout condition, indicating a possible carry-over effect from the timeout conditions.

When the completion of the initial link produced an immediate timeout ( 0 -s delay), initial-link responding was enhanced relative to baseline for all 8 rats. The mean elevation was $49 \%$, with a minimum of $15 \%$ (Rat C8) and a maximum of 108\% (Rat C2). Mean elevations were calculated by obtaining the difference between the median initial-link and baseline response rates and then dividing that difference by the median baseline response rate. Replications of this condition produced more dramatic initial-link elevations for Rats $\mathrm{C} 1, \mathrm{C} 5, \mathrm{C} 7$, and $\mathrm{C} 8$. The mean initial-link elevation in the replication condition was 99\%, with a minimum of 36\% (Rat C6) and a maximum of $210 \%$ (Rat C7).

The effects of the delayed timeout on initial-link responding varied across rats. Across delay values, initial-link elevations were small and unreliable for Rats C1, C3, C4, C6, and C7, 

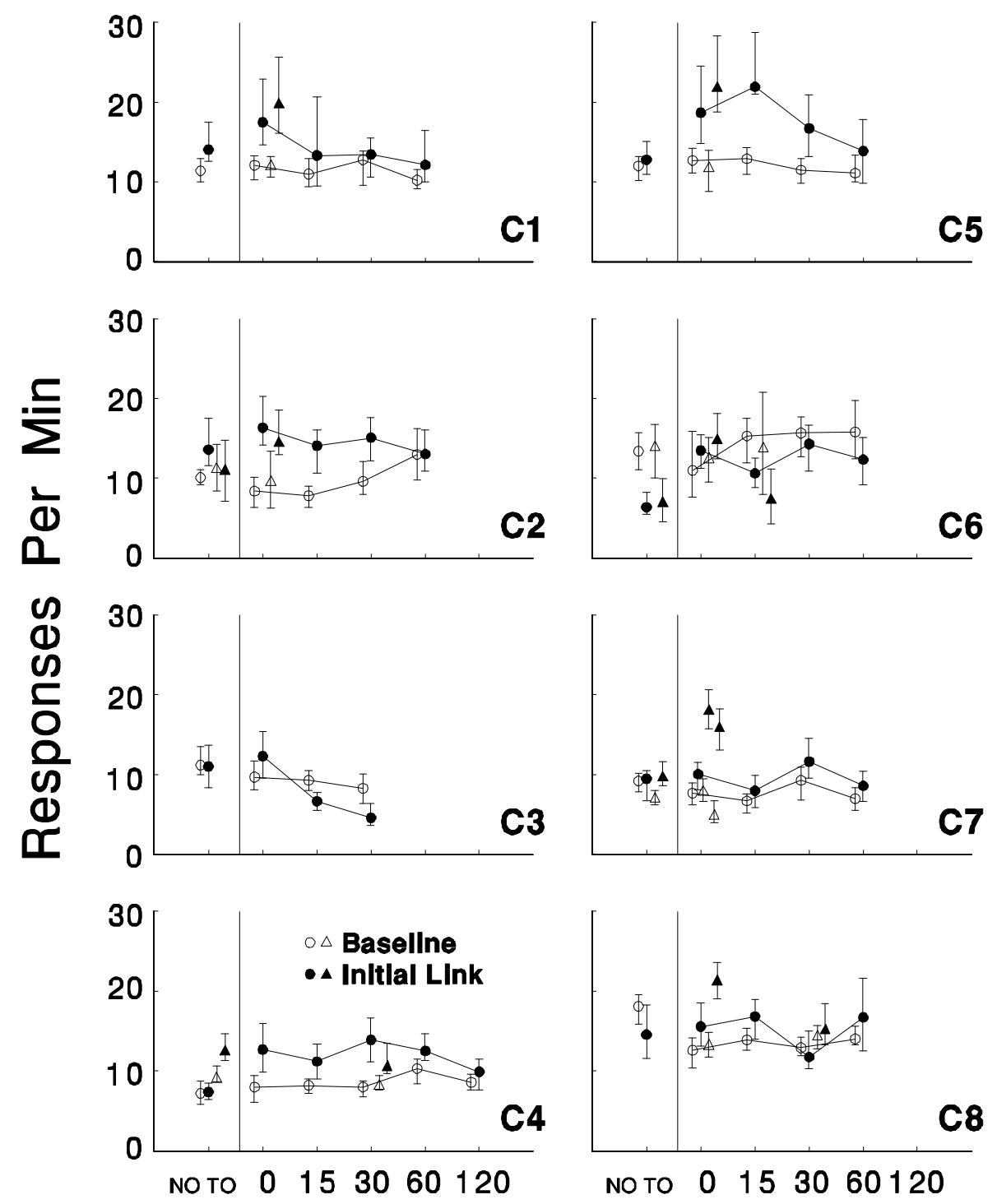

Delay (s)

Figure 1. Median and interquartile range of the 36 baseline and intial-link response rates (responses per min) comprising the stable 6 sessions of each condition. Solid symbols indicate initial-link response rates. Empty symbols indicate baseline response rates. Triangles represent replications. 
relative to both the baseline and the no-timeout condition. That is, even at the shortest delay (15 s), elevated initial-link response rates either were not found or were within the range of elevation obtained in the no-timeout conditions. On the other hand, the behavior of Rats C2, C5, and C8 show control by the delayed timeout. For Rats C2 and C5, initial-link elevations were evident at the 15-s and 30-s delays. Rat C8 had elevated initial-link response rates at the 15-s delay.

The relation between initial-link and baseline responding is explored further in Figure 2, which presents the median ratio of initial-link to baseline response rates across conditions. Reference lines represent the median ratios obtained during the no-timeout conditions. Expressing the data in terms of a ratio allows assessment of the effects of the delayed timeout by examining the slope of the obtained function.

Figure 2 shows that, for all rats, the greatest initial-link to baseline ratio occurred in the 0-s delay condition. For Rats C2 and C5, the obtained ratios were a decreasing function across delay values, intercepting the no-timeout reference line around the 60-s delay. A decreasing function also was observed in the results from Rat C3, however, only the ratio at the 0-s delay was elevated relative to the no-timeout reference line. Excluding the data from the 0-s delay condition, relatively flat functions at or below the reference lines indicate behavior not under control of the delayed timeout. This pattern of results can be seen in the behavior of Rats C1, C4, C6, and C7. The function obtained from Rat C8 also is relatively flat, although the ratios were greater than those obtained from the no-timeout condition.

Figure 3 presents the group mean of the initial-link to baseline ratios across conditions. Group means are based on the median ratios for each rat. In cases where conditions were replicated, the mean of the two medians was used for the purposes of calculating the group mean. Thus, with the exception of the 60-s delay condition, all group means are based on 8 median scores. The group mean from the 60-s delay condition is based on 7 median scores, as C3 did not complete this condition. Because C4 was the only rat exposed to the 120-s delay condition, these data were excluded from the analysis. Error bars represent standard deviations.

Figure 3 shows that, with the exception of the 0-s delay condition, initial-link to baseline ratios were relatively undifferentiated across conditions. Paired t-tests, comparing the group mean at each delay value with the no-timeout control, revealed a significant effect only at the 0-s delay condition, $[\mathrm{t}(7)=6.95, \mathrm{p}<.01]$. The group elevation at the 0 -s delay condition was $66 \%$, 

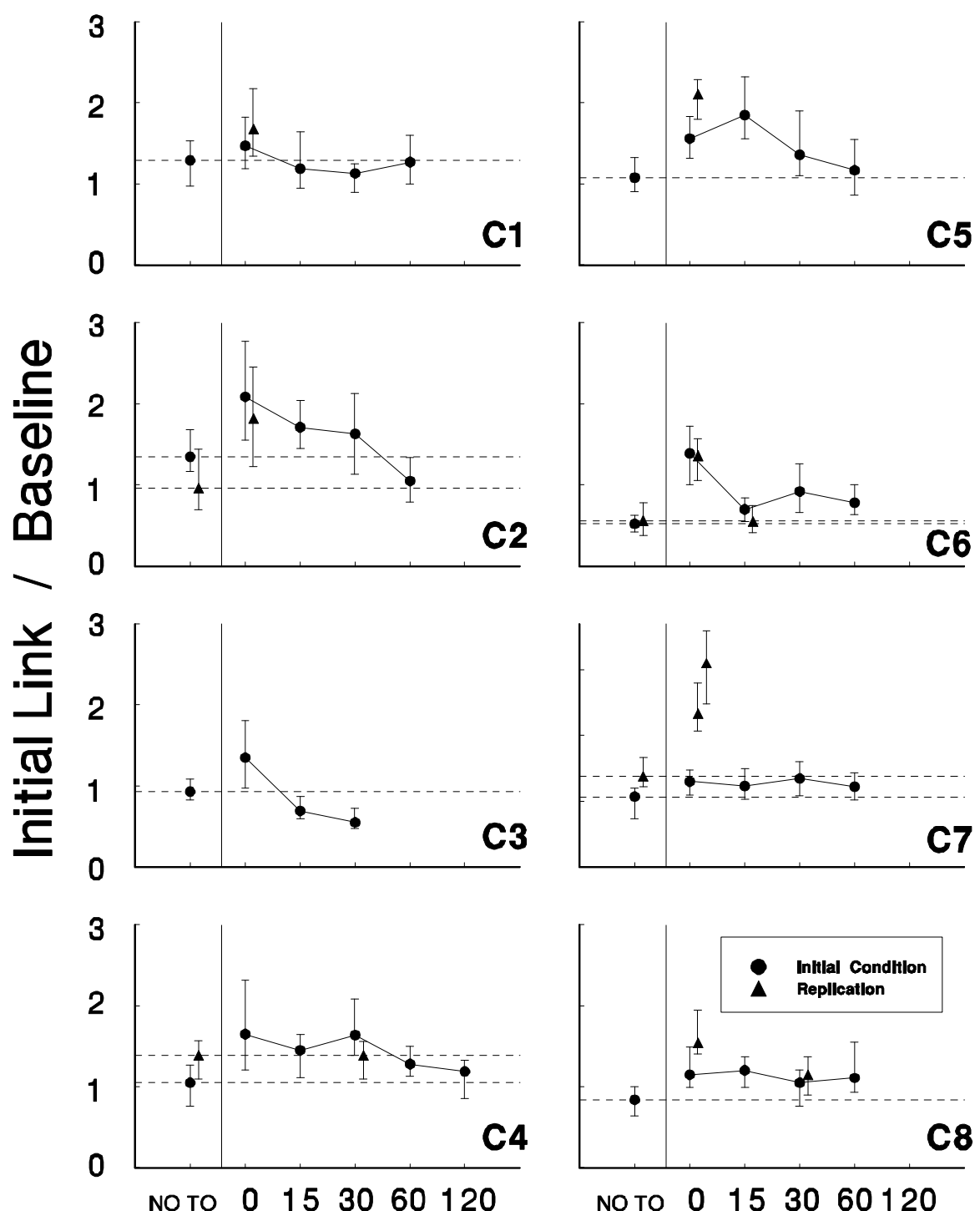

Delay (s)

Figure 2. Median and interquartile range of the 36 initial-link to baseline ratios of response rates (responses per min) comprising the stable 6 sessions of each condition. Triangles represent replications. 


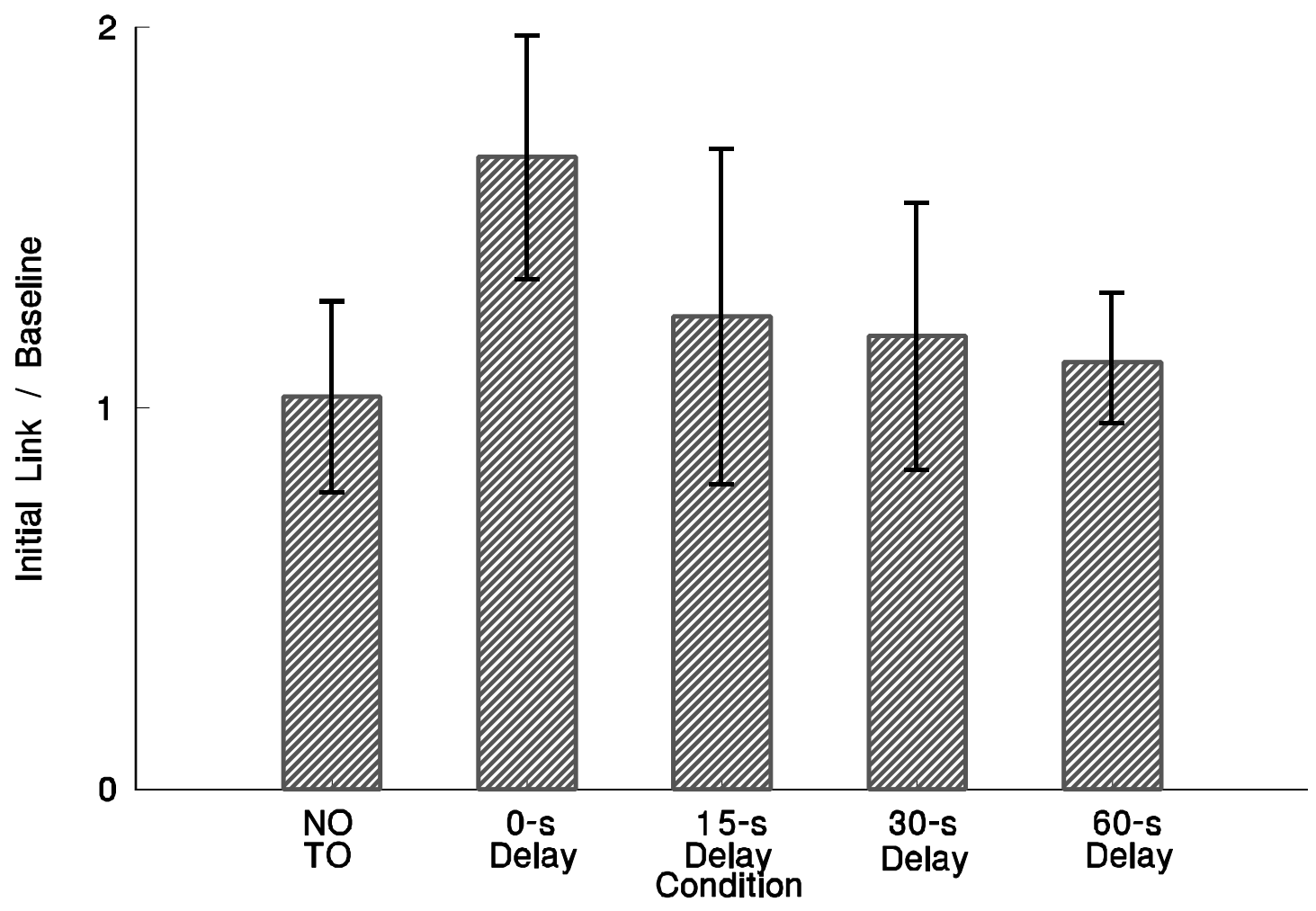

Figure 3. Group mean of the initial-link to baseline ratios of response rates (responses per min) across conditions. Error bars represent standard deviations.

similar to the magnitude of elevation reported by DeWaard et al. (1979). Across rats, the results presented in Figures 1 - 3 show that initial-link elevations were reliable only at the 0-s delay, although evidence of control by the delayed timeout was found in the behavior of Rats C2, C5, and to a lesser extent, C8. Figures 4 - 7 offer a more molecular analysis of the initial-link elevations, by examining latencies to respond from the onset of the initial link and run rates after the first response in the initial link.

\section{Latency to Respond in the Initial Link}

Figure 4 shows the median latency to respond from the onset of the initial link. Reference lines, drawn at the median initial-link latencies during the no-timeout conditions, provide a basis of determining if the timeout contingency decreased latencies to respond in the initial link. 


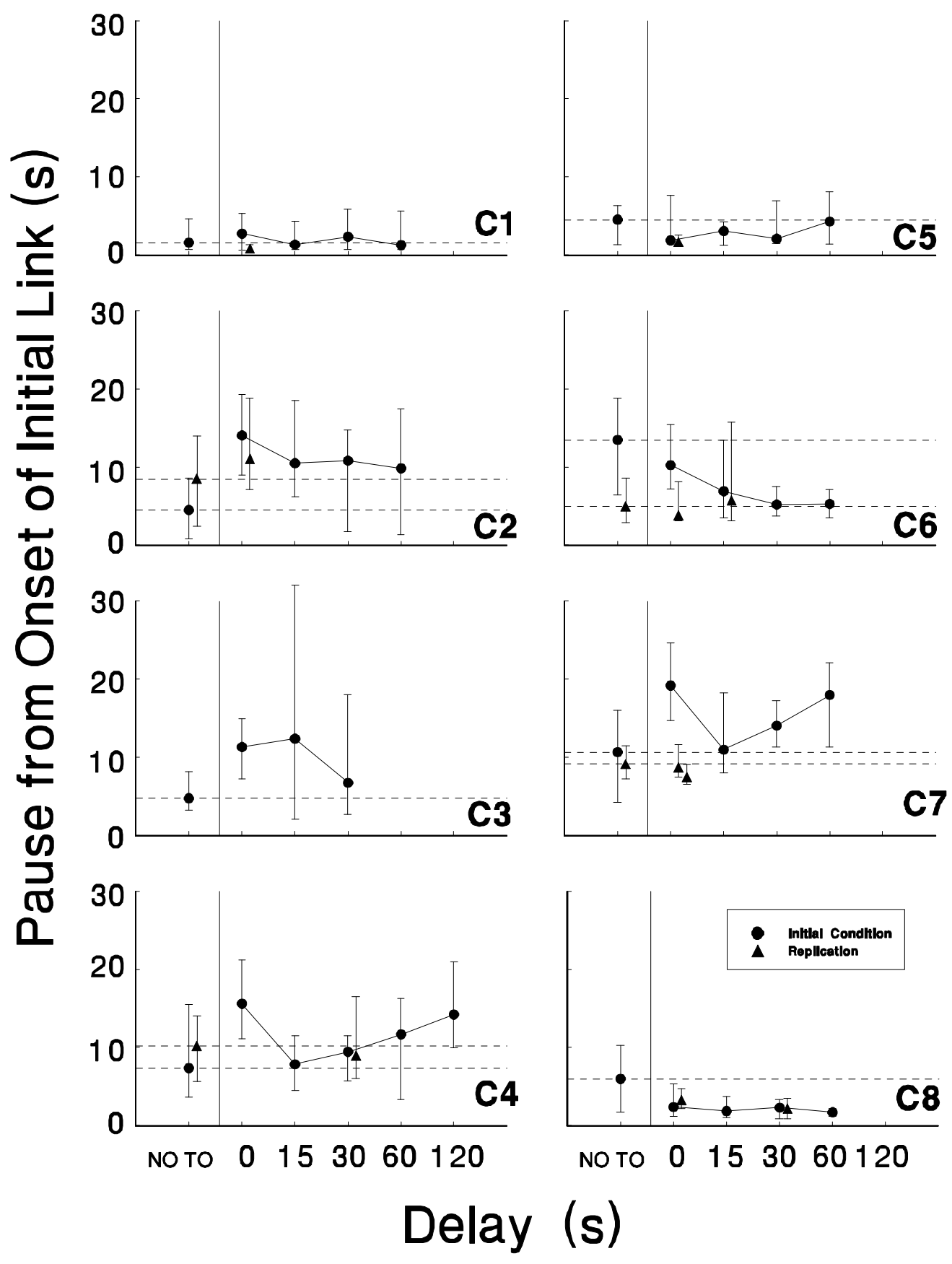

Figure 4. Median and interquartile range of the 36 latencies to respond from the onset of the initial link, comprising the stable 6 sessions of each condition. Latencies were measured to the nearest 1/100 of a second. Triangles represent replications. 


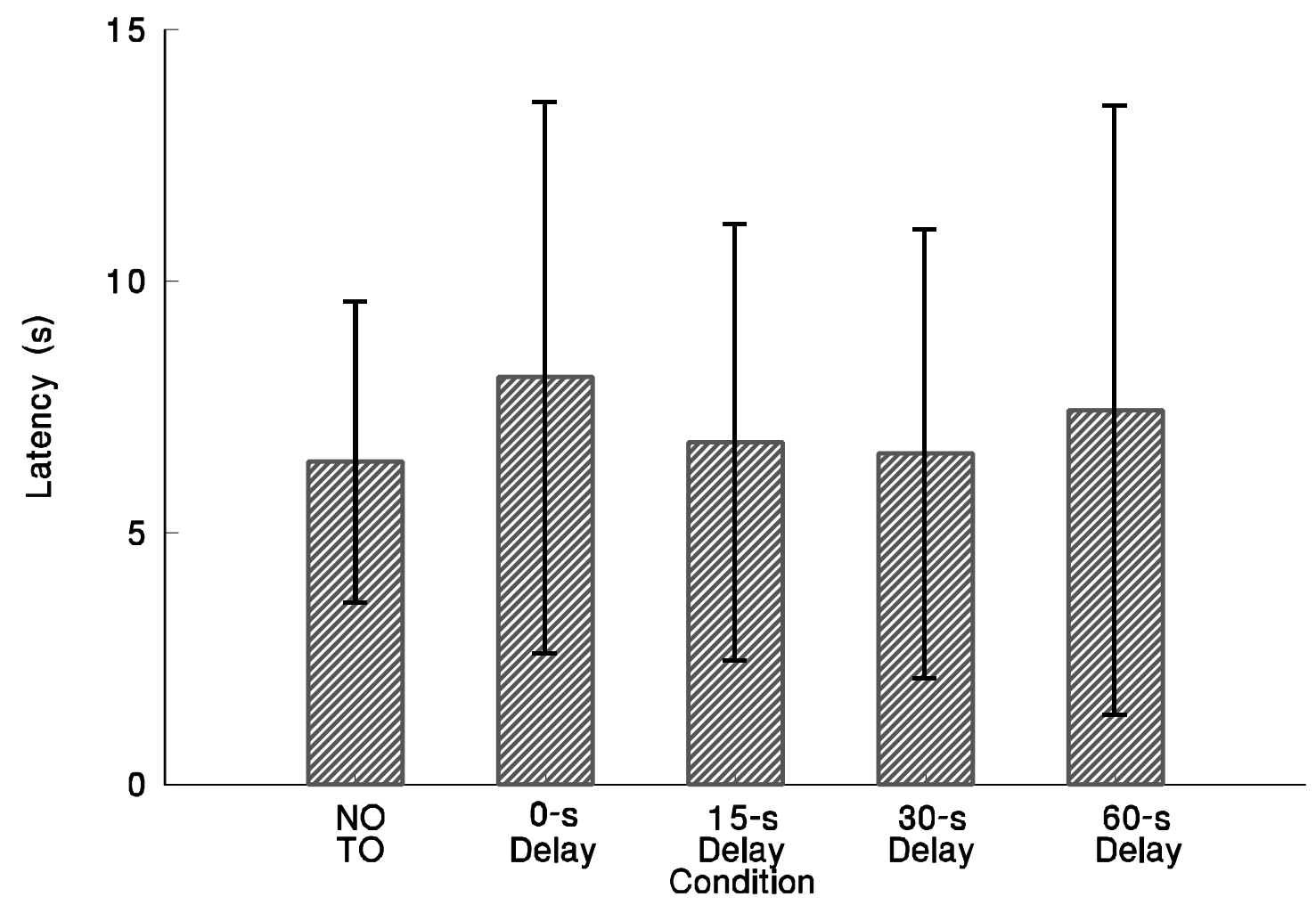

Figure 5. Group mean of the latency to respond from the onset of the initial link across conditions. Error bars represent standard deviations.

Latencies were highly variable between and within subjects. There was no consistent effect of delay on latency (i.e. most functions were relatively flat), and no reliable order effect (e.g. a general increase or decrease in latencies) was evident. These findings are summarized in Figure 5, which shows the group latency to respond in the initial link across conditions. The procedure of calculating group means was identical to the one described in the description of Figure 3. Across conditions, the mean latency to respond in the initial link remained relatively constant, but was characterized by a high degree of variability. Paired t-tests, comparing the mean latency in each delay condition with the no-timeout condition, failed to reveal any significant effects.

\section{Initial-Link Run Rates}

Figure 6 presents the median run rates in the initial link across delay conditions. Run 

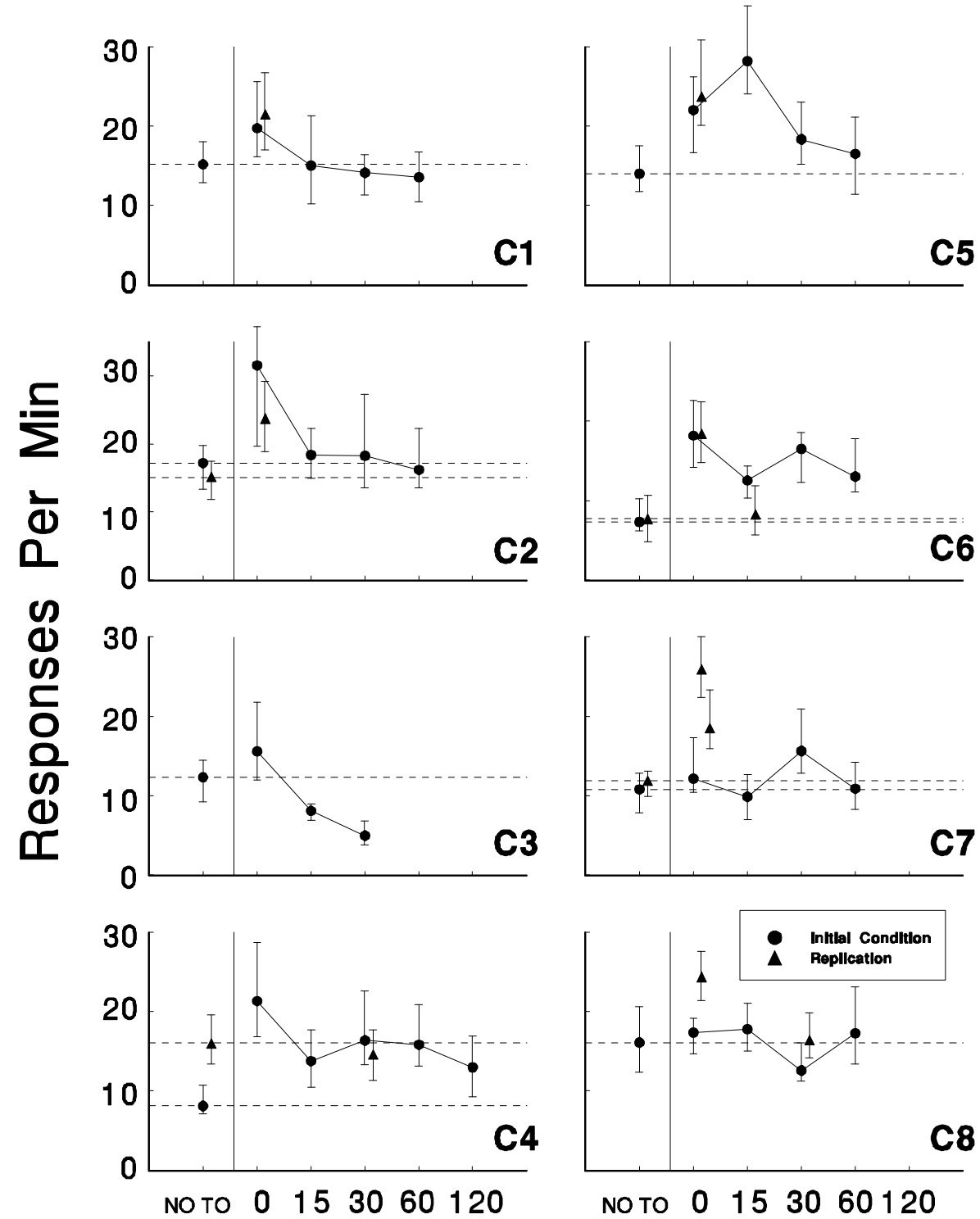

Delay (s)

Figure 6. Median and interquartile range of the 36 initial-link run rates comprising the stable 6 sessions of each condition. Run rates were calculated by dividing the total number of initial-link responses by the time to complete the initial link, excluding the pre-ratio pause. Triangles represent replications. 
rates reflect the response rates in the initial link excluding the pre-ratio pause. Reference lines indicate the median run rates in the no-timeout conditions. In general, an analysis of the run rates reveals the same general findings shown in the overall response rates (Figure 1). When timeout was presented immediately upon completion of the initial link ( 0 -s delay) run rates were elevated relative to the no-timeout control condition for all rats. Only Rat C5, however, showed elevated run rates across the delay conditions. The run rates from Rat $\mathrm{C} 2$ also can be considered elevated if the first no-timeout condition (in which a bias for the baseline stimulus developed) is excluded.

Interestingly, the run rates for Rat $\mathrm{C} 8$ were not elevated relative to the no-timeout condition. Thus, the elevation in overall response rates evident in Figures 1 and 2 can be attributed entirely to a decrease in the latency to respond in the initial link (see Figure 4). In addition, the run rates from Rats $\mathrm{C} 4$ and $\mathrm{C} 6$ were elevated relative to the first no-timeout condition, but were judged unreliable due to replications of either the no-timeout condition (Rat C4) or the 15-s delay condition (Rat C6).

Figure 7 presents the group run rates across conditions. Paired t-tests revealed that the run

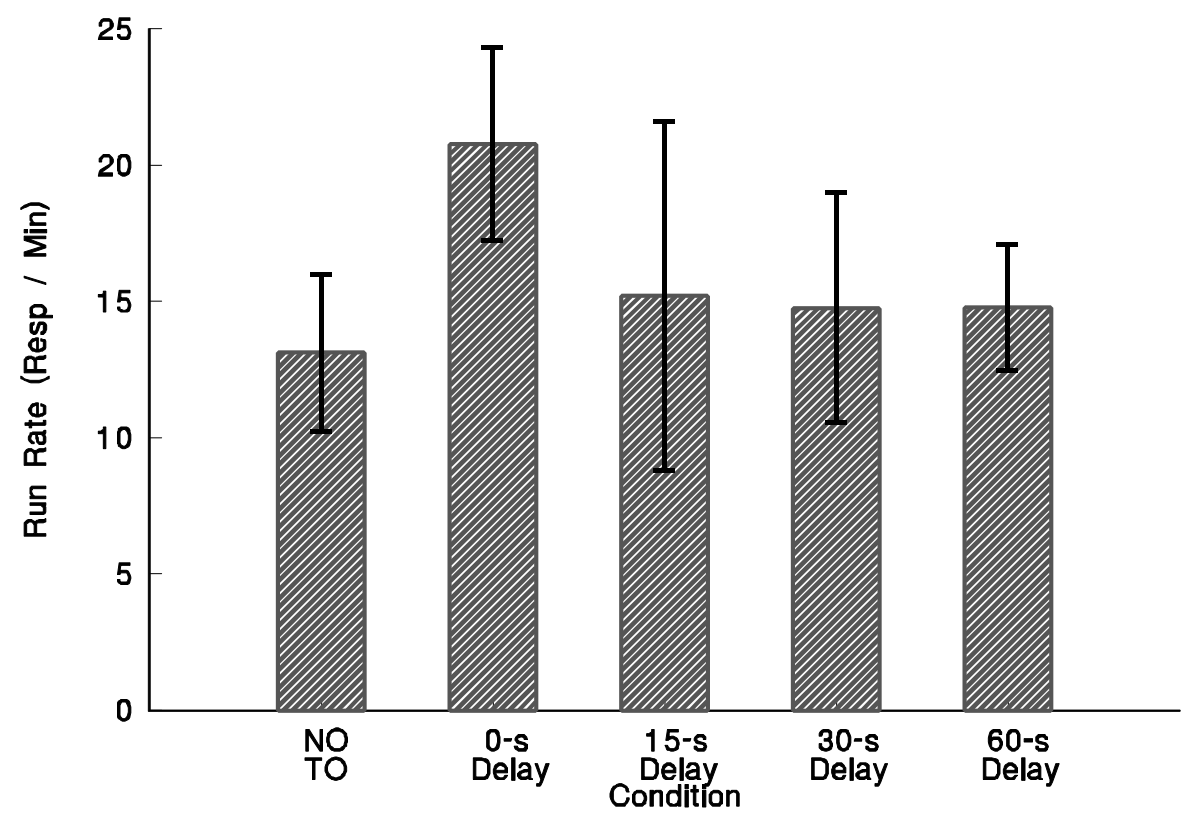

Figure 7. Group mean of initial-link run rates across conditions. Error bars represent standard deviations. 
rates in the 0-s delay condition were significantly greater than the run rates in the no-timeout condition, $[\mathrm{t}(7)=7.38, \mathrm{p}<.01]$. No other effects were statistically significant.

In conclusion, initial-link elevations occurred reliably only when the timeout was presented immediately upon the completion of the initial link, although the behavior of Rats C2 and C5 illustrate control by the delayed timeout at delay values up to $30 \mathrm{~s}$. For the most part, the observed initial-link elevations were not the result of a decreased latency to respond in the initial link, but rather the result of an overall increase in initial-link run rates.

\section{Terminal-Link Response Rates}

Of additional interest is the behavior during the delay to timeout, that is, during the $\mathrm{VC}$ portion of the terminal link. Figure 8 shows the median response rates during the terminal-link VC (closed circles) relative to baseline (open circles) across delay values. In general, terminal-link response rates were more variable, but comparable to baseline rates. Deviations from baseline may reflect adventitious reinforcement of responding (Rat C8) or pausing (Rat C5) by the onset of timeout.

\section{Timeout Response Rates}

Table 3 shows the response rates during timeout collapsed across delay values. Response rates during timeout were very low, as all rats discriminated the timeout from avoidance.

\section{Obtained Shock Rates and Avoidance Proficiency}

Table 4 shows the mean shocks per min in the baseline, initial-link, and terminal-link components of the chain schedule. Shock rates were based on overall session means from the stable 6 sessions. Overall avoidance proficiencies, based on the entire session, also were calculated. Proficiency was calculated by dividing the total number of canceled VC shocks by the total number of scheduled VC shocks. In general, the rats were proficient at avoiding shock (range $89 \%-99 \%$ ). For 6 of 8 rats (C1, C2, C3, C6, C7, and C8), shock rates were elevated slightly in the initial link relative to the baseline and terminal link, but this probably is an artifact of the shorter durations spent in the initial link relative to the baseline and the terminal link. For 2 rats (C6 and C7), however, the obtained shock rate in the initial link was approximately twice the obtained shock rate during baseline. This may be due to the lower rate of responding in the initial link relative to baseline for Rat C6, and an increase in the latency to respond in the initial link across delay values for Rat C7. 

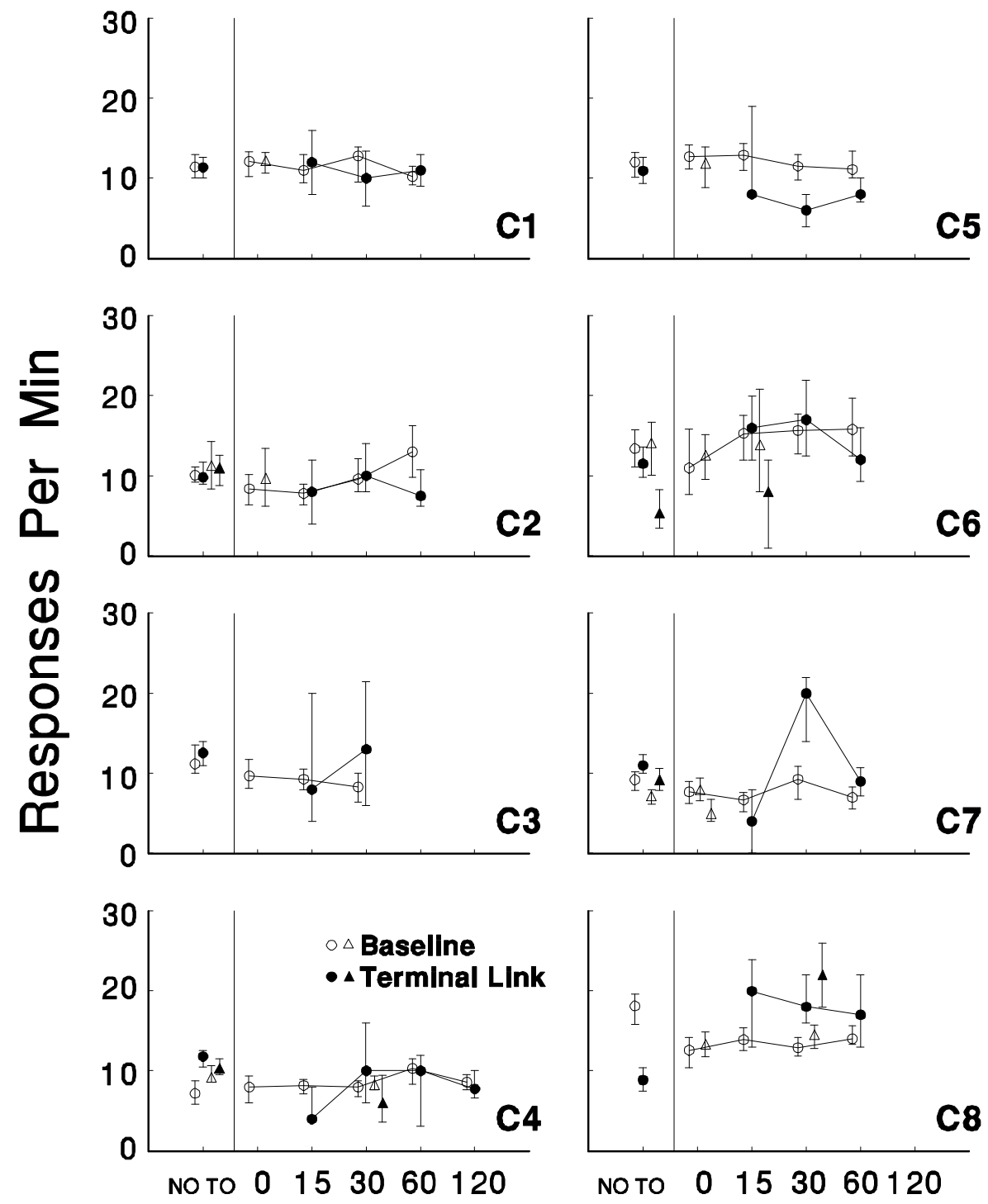

Delay (s)

Figure 8. Median and interquartile range of the 36 baseline and terminal-link response rates (responses per min) comprising the stable 6 sessions of each condition. Solid symbols indicate terminal-link response rates. Empty symbols indicate baseline response rates. Triangles represent replications. 
Table 3

Median response rates during timeout collapsed across conditions.

\begin{tabular}{cc} 
Rat & Median Responses Per Minute (Interquartile Range) \\
\hline \hline $\mathrm{C} 1$ & $0.07(0.04-0.12)$ \\
$\mathrm{C} 2$ & $0.02(0.00-0.08)$ \\
$\mathrm{C} 3$ & $0.09(0.02-0.15)$ \\
$\mathrm{C} 4$ & $0.00(0.00-0.03)$ \\
$\mathrm{C} 5$ & $0.03(0.00-0.13)$ \\
$\mathrm{C} 6$ & $0.03(0.00-0.07)$ \\
$\mathrm{C} 7$ & $0.08(0.04-0.15)$ \\
$\mathrm{C} 8$ & $0.03(0.00-0.07)$ \\
\hline \hline
\end{tabular}

Table 4

Obtained shock rates and overall proficiency in the baseline, initial, and terminal links collapsed across conditions

\begin{tabular}{ccccc} 
& \multicolumn{2}{c}{ Mean Shocks Per Minute (SD) } & \\
\cline { 2 - 4 } Rat & Baseline & Initial Link & Terminal Link & Proficiency \\
\hline \hline C1 & $0.00(0.01)$ & $0.01(0.05)$ & $0.00(0.00)$ & $98.88(1.02)$ \\
C2 & $0.12(0.08)$ & $0.13(0.22)$ & $0.08(0.14)$ & $88.90(3.72)$ \\
C3 & $0.01(0.02)$ & $0.03(0.06)$ & $0.00(0.01)$ & $96.70(2.69)$ \\
C4 & $0.08(0.05)$ & $0.07(0.10)$ & $0.07(0.13)$ & $90.04(3.65)$ \\
C5 & $0.00(0.01)$ & $0.00(0.00)$ & $0.00(0.01)$ & $99.31(0.71)$ \\
C6 & $0.08(0.06)$ & $0.19(0.23)$ & $0.06(0.11)$ & $93.59(4.63)$ \\
C7 & $0.09(0.05)$ & $0.18(0.37)$ & $0.06(0.10)$ & $88.32(4.05)$ \\
C8 & $0.02(0.03)$ & $0.04(0.10)$ & $0.05(0.13)$ & $97.22(1.40)$ \\
\hline \hline
\end{tabular}




\section{Resistance to Change in Schedules of Avoidance and Escape}

Finally, although not an aim of the present study, the change from the VC 60-s to VC 120-s schedule in the immediate timeout condition for Rats C1, C3, and C5 allows for an examination of the resistance to change in timeout and avoidance responding when the underlying shock avoidance schedule is altered. Using a two-lever procedure, Galizio (1999) reported that escape (timeout responding) was more resistant to extinction than avoidance behavior. The present analysis extends Galizio's finding to a one-lever procedure involving changes in reinforcement rate. Figure 9 shows the response rates in the baseline and initial link, graphed as a $\log$ proportion of the VC 60 schedule, across the first 10 sessions of VC 120. Initial-link responding was more resistant to change than baseline responding for Rats $\mathrm{C} 1$ and $\mathrm{C} 5$, and tended in that direction for Rat C3.

Figure 9. Log proportion of the mean initial-link and baseline response rates (responses per min) obtained from the variable-cycle 60-s schedule across the first 10 sessions of the variable-cycle $120-s$ schedule. Solid symbols indicate initiallink response rates. Empty symbols indicate baseline response rates.

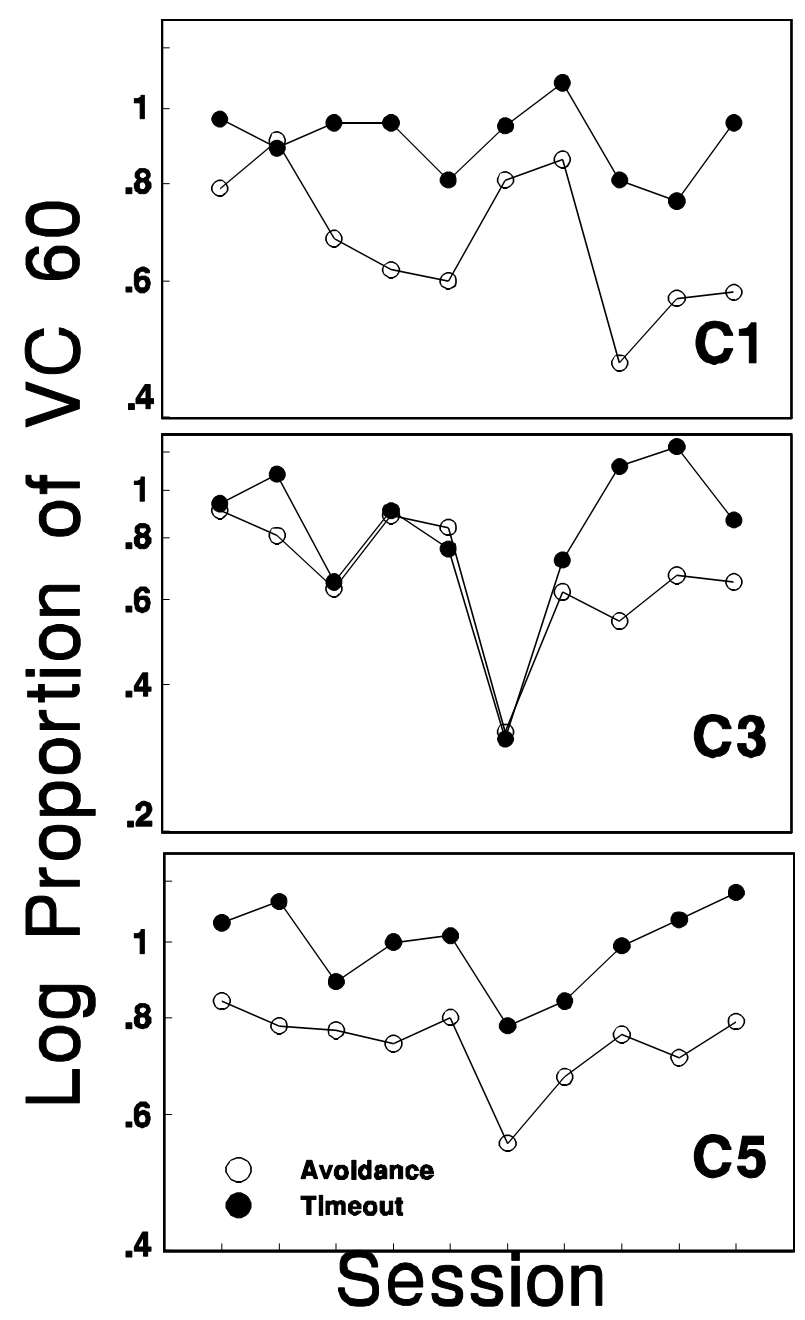




\section{Discussion}

\section{Session Reduction Revisited}

Mellitz et al. (1983) reported that rats' avoidance behavior tracked a superimposed schedule of session-reduction, in which responses on one lever postponed shock while responses on a second lever postponed shock and subtracted $1 \mathrm{~min}$ from the overall session time. These results suggest molar control of a pattern of responding by a temporally extended, delayed consequence. Employing a steady-state design with more stringent stability criteria, Perone and Day (1986) failed to replicate Mellitz et al.'s findings, even with the addition of molecular contingencies at the very end of the session.

The present research constituted a further attempt to replicate the findings of Mellitz et al. (1983) on a more local scale. In doing so, several procedural problems were eliminated. First, in light of Verhave's (1961) results, a one-lever procedure eliminated preference as the main dependent measure. Second, by conceptualizing session-reduction as an extended timeout at the termination of an avoidance session, the amount of session-reduction was controlled experimentally and presented more than once per session. Most importantly, the experimental design attempted to maximize control by the delayed timeout from avoidance by employing a signaled delay, investigating relatively short delays compared to those found in session-reduction procedures, and presenting the timeout more than once per session. The data-analytic techniques, including the use of group comparisons and statistical tests, were performed to maximize the chance that sensitivity to the delayed timeout would be detected.

Nonetheless, control by the delayed timeout was weak and unreliable across rats. The behavior of 5 of the rats was not clearly under the control of the delayed timeout at the shortest delay ( $15 \mathrm{~s}$ ). Only the behavior of Rats C2 and C5 suggest sensitivity to the timeout at a delay of $30 \mathrm{~s}$. Even when initial-link response rates were elevated relative to baseline (indicating control by the delayed timeout), these elevations were usually small in magnitude and highly variable.

The obtained results cast doubt on the interpretation of Mellitz et al.'s (1983) findings. In Mellitz et al.'s experiment, contact with session-reduction occurred at least minutes, and sometimes over an hour, into the session. Moreover, session offset was far removed from the pattern of responding that produced the session-reduction. In the present study, behavior was not sensitive to a timeout delayed by seconds, even though the opportunity to produce the timeout 
was signaled by a flashing houselight, the animals had a history of producing an immediate timeout in the presence of the flashing houselight, and the delay to timeout was mediated by a signal (houselight on or off). These findings, in combination with previous replication failures (Perone \& Day, 1986) and the methodological inadequacies of Mellitz et al.'s experiment (as discussed in the Introduction), call into question the interpretation of Mellitz et al.'s results as evidence of molar control.

\section{Conditioned Reinforcement}

To this point, elevated initial-link rates across delays have been interpreted as evidence of control by the delayed timeout. However, the terminal-link stimulus could have acquired conditioned reinforcing value through delay reduction (Fantino, 1977), as it signaled a reduction in the overall delay to timeout. Thus, initial-link elevations could have been maintained by the presentation of the terminal-link stimulus rather than by the delayed timeout. The fact that initial-link elevations were weak and unreliable across subjects despite the possible conditioned reinforcing value of the terminal-link stimulus is further evidence of the degraded reinforcing value of the delayed timeout.

\section{Shock-Frequency Reduction vs. Effort Reduction}

The results obtained from the 0-s delay condition replicated previous work using an FR schedule of timeout presentation conjointly arranged on an avoidance schedule (DeWaard et al., 1979), and showed that timeout from avoidance can have powerful reinforcing effects on behavior. Of theoretical interest is what properties determine the reinforcing value of timeout from avoidance. Traditional accounts have posited shock-frequency reduction as the reinforcer for avoidance and timeout responding (de Villiers, 1974; Herrnstein \& Hineline, 1966). More recent experiments have provided evidence that effort reduction, rather than shock-frequency reduction, may establish timeout from avoidance as a reinforcer (Courtney \& Perone, 1992; Perone \& Galizio, 1987; Perone \& Crawford, 1999).

The present results provide support for the effort-reduction account of timeout responding. As can be seen by Table 4, obtained shock rates were low, comparable to the obtained shock rates reported elsewhere (Courtney \& Perone, 1992; Perone \& Galizio, 1987; Perone \& Crawford, 1999). The mean obtained shock rate during the baseline segment of the chain schedule was 0.05 shocks per min, with a range from 0.00 to 0.12 shocks per min. It is 
difficult to imagine that shock-frequency reductions of this magnitude can be responsible for the pronounced initial-link elevations at the 0-s delay condition. Indeed, in a systematic replication of Herrnstein and Hineline's (1966) experiment, Myers and Perone (1998) showed that shock-frequency reductions of similar magnitudes will not maintain avoidance responding. Moreover, in a generalized matching law analysis of timeout from VC avoidance, Courtney and Perone (1992) reported greater sensitivity to effort reduction than shock-frequency reduction when the scheduled shock rate was manipulated across conditions.

\section{Molecular Patterns of Responding}

The present experiment also examined the pattern of responding generated by the FR schedule of timeout presentation. Previous research, maintaining timeout responding on fixed-interval schedules (Findley \& Aimes, 1965), variable-interval (VI) schedules (Galizio \& Perone, 1987; Perone \& Galizio, 1987), FR schedules (Sidman, 1962b), variable-ratio (VR) schedules (Galizio, 1999; Galizio \& Allen, 1991), and progressive-ratio (PR) schedules (Posner \& Baron, 1981), generated response patterns similar to those typically obtained in positive reinforcement preparations. That is, break-and-run patterns were observed using FR and PR schedules, high rates were obtained using VR schedules, and moderate rates were found when timeout was scheduled on a VI schedule.

Responding maintained on FR schedules of positive reinforcement is characterized by a post-reinforcement pause (break) followed by a consistent high rate of responding (run). An analysis of the run rates showed that run rates increased when timeout was presented immediately upon completion of the initial link, relative to when timeout was delayed or not scheduled.

The effects of the timeout on initial-link pausing are less clear. In procedures using positive reinforcement, the size of the post-reinforcement pause is directly related to the size of the ratio requirement. Because the ratio requirement in the present study was small, it was hypothesized that pauses would be relatively short in duration. Moreover, to the extent that timeout functioned as a reinforcer, the latency to respond in the initial link should decrease relative to the latency obtained in the no-timeout condition. This hypothesis was not supported by the pausing analysis in Figures 4 and 5. Latency to respond in the initial link was not related to the availability of timeout upon the completion of the FR requirement. Rather, it appears that the latency to respond in the initial link was controlled by the ongoing avoidance schedule. 
If the latency to respond in the initial link was controlled by the avoidance schedule, there should be a correspondence between latency and avoidance proficiency. On VC schedules, the magnitude of the average interresponse time (IRT) is inversely related to avoidance proficiency. That is, pausing for extended periods of time after responding is more likely to be followed by shock than responding at relatively short IRTs. Figure 4 and Table 4 suggest this relation. The rats with the shortest latencies to respond in the initial link (Rats C1, C5, and C8) also had the highest avoidance proficiencies. A relation between increased initial-link latency and decreased proficiency cannot be determined, however, as all rats were proficient at avoiding shock.

The variability in the latency data also can be accounted for by the molecular features of the VC schedule. For example, when a shock coincided with initial-link onset, the latency to respond in the initial link may have been short relative to when the initial-link onset coincided with an extended shock-free period. If variability in the latency data is determined by the presence of shock immediately preceding or coinciding with initial-link onset, then rats with the highest avoidance proficiencies should exhibit less variable latency data. This relation is evident for Rats C1 and C8, and to some extent for Rat C5.

Thus, the failure to obtain the classic break-and-run pattern should not be surprising, as the FR schedule was superimposed on an ongoing avoidance schedule. Using a conjoint schedule of timeout presentation, Baron and Trenholme (1971) failed to demonstrate scalloping on an FI schedule of timeout presentation superimposed on a Sidman avoidance schedule. The experiments cited above as demonstrating schedule control over timeout responding employed a two-lever procedure, where timeout was the sole consequence of responding on one of the levers. In a single-lever procedure where timeout is arranged conjointly on an ongoing avoidance schedule, both the schedule of timeout delivery and the avoidance schedule interact to determine the final pattern of responding (Perone \& Galizio, 1987).

Although initial-link response strength was determined by both the avoidance schedule and the schedule of timeout delivery, the resistance to change data in Figure 9 suggest some independence between the two schedules. Responding in the initial link was more resistant to a decrease in the scheduled shock rate than responding during baseline. This finding is consistent with findings reported by Galizio (1999), who investigated the resistance to extinction between timeout and avoidance responding using a two-lever preparation. In Galizio's procedure, rats' 
presses on one lever postponed shock while presses on a second lever produced a timeout from avoidance on a VR schedule. In the experimental condition, all scheduled shocks were omitted (extinction). While response rates on the avoidance lever extinguished within a few sessions, in some cases responding on the timeout lever persisted for more than 100 sessions. The results shown in Figure 9 represent a systematic replication of Galizio's finding using a one-lever procedure and a decrease in reinforcement rate as the disrupter.

\section{Adventitious Reinforcement of Responding during the Delay to Timeout}

Of additional interest is the behavior during the delay to timeout (Figure 8). Although more variable, terminal-link response rates generally were similar to baseline response rates. At the shorter delays, the variability in terminal-link responding is in part an artifact of the procedure. In some instances, however, terminal-link response rates were elevated (Rat C8) or suppressed (Rat C5) relative to baseline across most delay values. This could reflect adventitious reinforcement of responding or pausing by the presentation of timeout. These findings are consistent with results reported by Baron and Trenholme (1971), where a fixed-time (FT) schedule of timeout presentation was arranged conjointly on an avoidance schedule. Although the timeout presentation was response independent, responding during the FT initial link was enhanced in some rats, although the elevations were small and unreliable across subjects.

\section{Delayed Reinforcement}

Finally, the present results extend the literature on delayed reinforcement with respect to timeout from avoidance. At first blush, it may appear as if responding maintained by delayed positive reinforcement persists at greater strength than responding maintained by delayed negative reinforcement. Procedures using positive reinforcement have shown that signaled delays as long as 1 min can have little systematic effect on response rate (Ferster, 1953; Lattal, 1984; Schaal \& Branch, 1988, 1990). In the present experiment, control by the delayed timeout was not reliable at a 15-s delay. However, the discrepant findings probably are due more to procedural differences than inherent differences between positive and negative reinforcement. Most notably, in the positive reinforcement preparation, reinforcement is contingent upon responding. In the present procedure, timeout presentation was not contingent upon elevated initial-link response rates. Responding on the baseline avoidance schedule ensured timeout delivery independent of control by the delayed timeout. 
In this respect, the effects of delay on responding to produce timeout from avoidance could be assessed better in a two-lever preparation. Responding on one lever would postpone shock, while responding on a second lever would produce a timeout on a compound schedule in which the second component of the compound schedule would be an FT schedule (delay). In this procedure, control by the delayed timeout could be assessed directly. Experimentation on acquisition of delayed negative reinforcement also could utilize this procedure.

\section{Summary}

To summarize, when completion of the initial link produced an immediate timeout, initial-link response rates were elevated relative to baseline. When the timeout was delayed, initial-link elevations were weak and unreliable across rats. This pattern of results underscores the importance of contiguity as a determining factor of the reinforcing value of reduced contact with schedules of shock avoidance, and casts doubt on the reliability of results positing session-reduction as negative reinforcement. 


\section{References}

Anger, D. (1963). The role of temporal discriminations in the reinforcement of Sidman avoidance behavior. Journal of the Experimental Analysis of Behavior, 6, 477-506.

Baron, A. (1991). Avoidance and punishment. In I. H. Iversen \& K. A. Lattal (Eds.), Experimental analysis of behavior (Part 1, pp. 173-217). Amsterdam: Elsevier.

Baron, A., \& Trenholme, I. A. (1971). Response-dependent and response-independent timeout from an avoidance schedule. Journal of the Experimental Analysis of Behavior, 16, 123 131.

Courtney , K., \& Perone, M. (1992). Reductions in shock frequency and response effort as factors in reinforcement by timeout from avoidance. Journal of the Experimental Analysis of Behavior, 58, 485-496.

de Villiers, P. A. (1972). Reinforcement and response rate interaction in multiple random-interval avoidance schedules. Journal of the Experimental Analysis of Behavior, 18, 499-507.

de Villiers, P. A. (1974). The law of effect and avoidance: A quantitative relationship between response rate and shock-frequency reduction. Journal of the Experimental Analysis of Behavior, 21, 223-235.

DeWaard, R. J., Galizio, M., \& Baron, A. (1979). Chained schedules of avoidance: reinforcement within and by avoidance situations. Journal of the Experimental Analysis of Behavior, 32, 399-407.

Dinsmoor, J. A. (1977). Escape, avoidance, punishment: Where do we stand? Journal of the Experimental Analysis of Behavior, 28, 83-95.

Fantino, E. (1977). Conditioned reinforcement: Choice and information. In W. K. Honig and J.E. R. Staddon (Eds.), Handbook on operant behavior. Englewood Cliffs, NJ: Prentice Hall.

Ferster, C. B. (1953). Sustained behavior under delayed reinforcement. Journal of the Experimental Analysis of Behavior, 45, 218-224.

Findley, J. D., \& Ames, L. L. (1965). A note on time out from avoidance with the chimpanzee. Journal of the Experimental Analysis of Behavior, 8, 419-423.

Fleshler, M. \& Hoffman, H. S. (1962). A progression for generating variable-interval schedules. Journal of the Experimental Analysis of Behavior, 5, 529-530.

Galizio, M. (1999). Extinction of responding maintained by timeout from avoidance. Journal of the Experimental Analysis of Behavior, 71, 1-11. 
Galizio, M., \& Allen, A. R. (1991). Variable-ratio schedules of timeout from avoidance: Effects of d-amphetamine and morphine. Journal of the Experimental Analysis of Behavior, 56, 193-203.

Galizio, M., \& Perone, M. (1987). Variable-interval schedules of timeout from avoidance: Effects of chlordiazepoxide, CGS 8216, morphine, and naltrexone. Journal of the Experimental Analysis of Behavior, 47, 115-126.

Herrnstein, R. J. (1969). Method and theory in the study of avoidance. Psychological Review, 76, 49-69.

Herrnstein, R. J., \& Hineline, P. N. (1966). Negative reinforcement as shock-frequency reduction. Journal of the Experimental Analysis of Behavior, 9, 421-430.

Hineline, P. N. (1984). Aversive control: A separate domain? Journal of the Experimental Analysis of Behavior, 42, 495-509.

Lattal, K. A. (1984). Signal functions in delayed reinforcement. Journal of the Experimental Analysis of Behavior, 42, 239-253.

Mellitz, M., Hineline, P. N., Whitehouse, W. G., \& Laurence, M. T. (1983). Duration-reduction of avoidance sessions as negative reinforcement. Journal of the Experimental Analysis of Behavior, 40, 57-67.

Myers, T. M., \& Perone, M. (1998). Assessing the limits of sensitivity to shock-frequency reduction as negative reinforcement. Unpublished master's thesis, West Virginia University.

Perone, M., \& Day, H. (1986, May). Molar response event relations in negative reinforcement. Symposium p In K.A. Lattal (Chair), Response-event relations across the behavioral spectrum. resented at the annual meeting of the Association for Behavior Analysis Convention, Milwaukee, WI.

Perone, M., \& Crawford, E. (1999). The role of intermittent shock-postponement in reinforcement by timeout from avoidance. Mexican Journal of Behavior Analysis, 25, 329-340.

Perone, M., \& Galizio, M. (1987). Variable-interval schedules of timeout from avoidance. Journal of the Experimental Analysis of Behavior, 47, 97-113

Posner, J., \& Baron, A. (1981, May). Progressive ratio schedules of positive and negative reinforcement in rats. Paper presented at the annual meeting of the Association for Behavior Analysis, Milwaukee, WI. 
Schaal, D. W., \& Branch, M. N. (1988). Responding of pigeons under variable-interval schedules of unsignaled, briefly signaled, and completely signaled delays to reinforcement. Journal of the Experimental Analysis of Behavior, 50, 33-54.

Schaal, D. W., \& Branch, M. N. (1990). Responding of pigeons under variable-interval schedules of signaled-delayed reinforcement: Effects of delay-signal duration. Journal of the Experimental Analysis of Behavior, 53, 103-121.

Sidman, M. (1953). Avoidance conditioning with brief shocks and no exteroceptive warning signal. Science, 118, 157-158.

Sidman, M. (1962a). Reduction of shock frequency as reinforcement for avoidance behavior. Journal of the Experimental Analysis of Behavior, 5, 247-257.

Sidman, M. (1962b). Time out from avoidance as a reinforcer: A study of response interaction. Journal of the Experimental Analysis of Behavior, 5, 423-434.

Verhave, T. (1961). Some observations concerning prepotency, and the probability of postponing shock with a two-lever avoidance procedure. Journal of the Experimental Analysis of Behavior, 4, 187-192. 